(C) Dereito Vol.28, n01:179-207 (Xaneiro-Xuño, 2019) • ISSN 1132-9947

\title{
LOS PROTOCOLOS DE PREVENCIÓN Y ACTUACIÓN FRENTE AL ACOSO POR RAZÓN DE GÉNERO EN LAS UNIVERSIDADES PERTENECIENTES A LA COMUNIDAD AUTÓNOMA DE GALICIA
}

The protocols against gender-based harassment in universities belonging to the galician autonomous community

DOI: http://dx.doi.org/10.15304/dereito.28.1.5612

Alicia Villalba SÁnChez ${ }^{1}$

Profesora Ayudante Doctora de Derecho del Trabajo y de la Seguridad Social Universidade de Santiago de Compostela

alicia.villalba@usc.es

\section{Resumen}

Entre los riesgos que amenazan la integridad física y psíquica del personal integrante de cualquier organización destacan, por su frecuencia y la gravedad de sus consecuencias, aquéllos de índole psicosocial. El ámbito universitario no es ajeno a tales riesgos, razón por la cual se ha dotado de instrumentos jurídicos que permiten articular una estrategia que garantice el desarrollo de la actividad docente e investigadora en un entorno adecuado. El protocolo destinado a la prevención y actuación frente al acoso se erige en la herramienta fundamental cuya evolución se abordará en este trabajo, tomando como referencia los aprobados por las tres universidades pertenecientes al ámbito territorial de la Comunidad Autónoma de Galicia.

Palabras clave: Universidad; Riesgos psicosociales; Acoso; Discriminación por razón de género; Protocolo de prevención y actuación.

\section{Abstract}

Among the risks that threaten the physical and psychological integrity of the staff members of any organization, those of a psychosocial nature have become especially relevant due to their frequent incidence and their serious consequences. Academia is not immune to such risks. For this reason, universities have provided themselves with legal instruments that allow articulating an adequate strategy that guarantees an appropriate environment for research and teaching. The protocol designed to prevent and act against harassment becomes a fundamental tool whose evolution will be addressed in this work, taking as a reference those approved by the three universities belonging to the territorial area of the Galician Autonomous Community.

Keywords: University; Psychosocial risks; Harassment; Gender-based discrimination; Preventive and defensive protocol.

\footnotetext{
${ }^{1}$ https://orcid.org/0000-0001-8188-4810

Este trabajo es fruto del Proyecto de investigación del MINECO, titulado "Nuevas (novísimas) tecnologías de la información y comunicación y su impacto en el mercado de trabajo: Aspectos emergentes en el ámbito nacional e internacional" (DER2016-75376R), cuya investigadora principal es la Profa. Lourdes Mella Méndez.
}

Recibido: 28/12/2018. Aceptado: 01/06/2019. 


\section{SUMARIO}

1.- INTRODUCCIÓN. 2.- LOS PROTOCOLOS CONTRA EL ACOSO DISCRIMINATORIO EN LAS UNIVERSIDADES PÚBLICAS DE LA COMUNIDAD AUTÓNOMA DE GALICIA. 2.1.- Declaración de principios. 2.2.- Ámbito de aplicación. 2.2.1.- Ámbito de aplicación material. 2.2.2.Ámbito de aplicación personal. 2.2.3.- Ámbito de aplicación espacial. 2.3.Medidas de prevención del acoso. 2.4.- Medidas de actuación frente al acoso. 2.4.1.- Procedimiento de actuación frente al acoso. 2.4.1.1.Órgano competente. 2.4.1.2.- Denuncia. 2.4.1.3.- Instrucción. 4.1.4.Adopción de medidas disciplinarias. 3.- CONCLUSIÓN.

\section{SUMMARY}

1.- INTRODUCTION. 2.- THE PROTOCOLS AGAINST DISCRIMINATORY HARASSMENT IN THE PUBLIC UNIVERSITIES OF THE AUTONOMOUS GALICIAN COMMUNITY. 2.1.- Statement of principles. 2.2.- Scope of application. 2.2.1.- Objective scope of application. 2.2.2.- Subjective scope of application. 2.2.3.- Territorial scope of application. 2.3.Measures to prevent harassment. 2.4.- Measures against harassment. 2.4.1.- Procedure against harassment. 2.4.1.1.- Competent authority. 2.4.1.2.- Complaint. 2.4.1.4.- Disciplinary measures. 3.- CONCLUSION.

\section{INTRODUCCIÓN}

La entrada en vigor de la Directiva 2000/43/CE del Consejo de 29 de junio de 2000 relativa a la aplicación del principio de igualdad de trato de las personas independientemente de su origen racial o étnico ${ }^{2}$ vino a paliar una carencia del ordenamiento jurídico español que, hasta ese momento, había eludido definir el acoso en tanto violencia ejercida en el ámbito laboral. Bien es cierto que el "comportamiento" descrito en su art. 2.3 constituye una especie perteneciente al género en torno al cual gira esta norma, a saber: la discriminación ${ }^{3}$. Y no cualquier discriminación, sino únicamente aquélla basada en el origen racial o étnico de la víctima. Será objeto de persecución, en virtud de esta disposición, aquel comportamiento "no deseado relacionado con el origen racial o étnico que tenga como objetivo o consecuencia atentar contra la dignidad de la persona y crear un entorno intimidatorio, hostil, degradante, humillante, $u$ ofensivo".

Su transposición al Derecho español que, según la propia Directiva 2000/43/CE, no podría llevarse a cabo más allá del día el 19 de julio de 2003, se articuló de forma paulatina. En un primer momento, la Ley $62 / 2003$, de 30 de diciembre, de medidas fiscales, administrativas y del

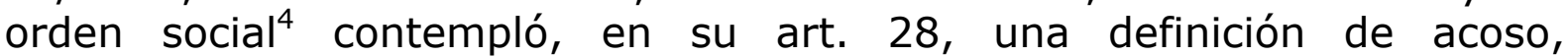
entendiendo por tal "toda conducta no deseada relacionada con el origen

\footnotetext{
2 DOCE L 180/22, de 19 julio 2000.

3 Aludiendo al acoso como "acto de discriminación": N. SERRANO ARGÜESO, "Dificultades para reconocer la presencia de acoso discriminatorio. El frecuente ejemplo del acoso por razón de sexo", Revista Doctrinal Aranzadi Social, vol. 4, no 7, 2011, pp. 88 y ss.

${ }^{4}$ BOE no 313, de 31 diciembre 2003.
} 
racial o étnico, la religión o convicciones, la discapacidad, la edad o la orientación sexual de una persona, que tenga como objetivo o consecuencia atentar contra su dignidad y crear un entorno intimidatorio, humillante u ofensivo"s. Se ofrece así un concepto que tampoco comprende todo tipo de violencia perpetrada en el entorno laboral pero que, a su vez, trasciende el ámbito de aplicación de la Directiva 2000/43/CE, al dar cabida a diversos detonantes de la conducta a la cual se refiere. La razón estriba en que esta norma hace las veces de instrumento de aplicación de lo dispuesto en la Directiva 2000/78/CE del Consejo, de 27 de noviembre de 2000, relativa al establecimiento de un marco general para la igualdad de trato en el empleo y la ocupación ${ }^{6}$. Ésta, en su art. 2.3, construye un concepto más amplio de acoso discriminatorio, aludiendo a nuevas causas, entre las cuales no figura el sexo de la víctima, ni tampoco su identidad de género, pero sí su orientación sexual.

Ha sido preciso aguardar hasta la promulgación de la Directiva 2002/73/CE del Parlamento Europeo y del Consejo, de 23 de septiembre de 2002, que modifica la Directiva 76/207/CEE del Consejo relativa a la aplicación del principio de igualdad de trato entre hombres y mujeres en lo que se refiere al acceso al empleo, a la formación y a la promoción profesionales, y a las condiciones de trabajo ${ }^{7}$, para obtener una mención al acoso debido al sexo, como factor de discriminación. En su art. 2 ha definido el "acoso" y el "acoso sexual". El primero, al que no añade adjetivo alguno, es el que posteriormente ha contemplado, con matices, la Ley Orgánica 3/2007, de 22 de marzo, para la igualdad efectiva de mujeres y hombres ${ }^{8}$-en adelante, LOI- en su art. 7.2. Aunque la Directiva parezca aludir al acoso en cuanto violencia en el trabajo ajena a todo móvil discriminatorio, una lectura del precepto basta para desmentir esta primera impresión, toda vez que se alude a "la situación en que se produce un comportamiento no deseado relacionado con el sexo de una persona con el propósito o el efecto de atentar contra la dignidad de la persona y de crear un entorno intimidatorio, hostil, degradante,

\footnotetext{
${ }^{5}$ Es de advertir que, con una escasa antelación a la entrada en vigor de esta norma, el legislador nacional había ya tipificado el acoso cuando éste era debido a la discapacidad de la víctima en el art. 7.a) de la Ley 51/2003, de 2 de diciembre, de igualdad de oportunidades, no discriminación y accesibilidad universal de las personas con discapacidad (BOE no 289, de 3 diciembre 2003), utilizando una técnica jurídica parecida. ${ }^{6}$ DOCE L 303, de 2 diciembre 2000.

7 DOCE L 269 de 5 octubre 2002. Conviene recordar la existencia de documentos previos a esta norma también concernientes al acoso sexual y por razón de sexo en el lugar de trabajo, como la Recomendación de la Comisión, de 27 de noviembre de 1991, relativa a la protección de la dignidad de la mujer y del hombre en el trabajo (DOCE L 049 de 24 febrero 1992); y también posteriores, como la Comunicación de la Comisión al Consejo y al Parlamento Europeo por la que se transmite el acuerdo marco europeo sobre el acoso y la violencia en el trabajo (COM/2007/0686 final). Véase L. MELLA MÉNDEZ, "Harassment Protocols in Spain: The Case of Universities", en AAVV, Psychosocial Risks in Labour and Social Security Law. A Comparative Legal Overview from Europe, North America, Australia and Japan, Springer, 2017, p. 197.
}

${ }^{8}$ BOE no 71, de 23 marzo 2007. 
humillante u ofensivo". Fue así como el sexo hizo su aparición en el ordenamiento jurídico español como causa de la conducta discriminatoria articulada a través del acoso. De ahí el acierto del legislador nacional cuando atribuyó a esta conducta la denominación de "acoso por razón de sexo". No obstante, la transposición de este concepto no estuvo exenta de matices. En concreto, el art. 7.2 LOI evita precisar que el comportamiento en cuestión deba ser "no deseado". Esta adaptación sugiere la existencia de acoso siempre y cuando pueda identificarse un comportamiento que haya provocado los efectos citados, sin que resulte determinante la voluntad de la víctima. Admitir la posición contraria equivaldría a dar por bueno el consentimiento de la víctima frente al acoso, sin tener en cuenta el desequilibrio jurídico que, en detrimento de la parte asalariada, subyace a la relación laboral, que convierte al consentimiento en una mera resignación. Consideraciones adicionales, relativas al estado psicológico de la víctima ${ }^{9}$ invitan a decantarse por una interpretación lo más objetiva posible de lo que ha de considerarse como acoso.

También de origen discriminatorio, pero específico en lo que atañe al contenido concreto de la conducta perpetrada, es el segundo tipo de acoso motivado por una discriminación basada en sexo. Se trata del "acoso sexual", igualmente denominado por el legislador de la Unión y el español. El primero se refiere a él como aquella "situación en que se produce cualquier comportamiento verbal, no verbal o físico no deseado de índole sexual con el propósito o el efecto de atentar contra la dignidad de una persona, en particular cuando se crea un entorno intimidatorio, hostil, degradante, humillante u ofensivo". Perfilando la anterior definición, la LOI suprime, como sucedía en el anterior tipo, la mención a su carácter "no deseado". Se añade, también como subespecie de acoso de origen discriminatorio motivado por el sexo de la víctima, el chantaje sexual, consistente en el condicionamiento "de un derecho o de una expectativa de derecho a la aceptación de una situación constitutiva de acoso sexual o de acoso por razón de sexo" (art. 7.4 LOI) ${ }^{10}$.

Con esta norma culmina el proceso de transposición que ha dado lugar a la tipificación del acoso, en tanto violencia habida en el entorno laboral mediante la cual se evidencia el trato discriminatorio que el acervo europeo pretendió atajar. Persiste, sin embargo, silente el legislador en cuanto concierne a la violencia perpetrada en el entorno laboral cuya causa no estribe en alguna de las que dan pie a una discriminación legal o constitucionalmente proscrita. Se alude al acoso, en cuanto género dentro del cual se inscribe el de origen discriminatorio, también denominado

\footnotetext{
9 R. VALLEJO DACOSTA, "Acoso sexual y acoso por razón de sexo: riesgos de especial incidencia en la mujer trabajadora", Trabajo: Revista andaluza de relaciones laborales, no 17,2006 , p. 61.

${ }^{10}$ Es de advertir que el acoso sexual era ya conocido por el legislador español que, antes de preverlo en la LOI, lo había tipificado como infracción muy grave en el art. 8.13 de la entonces vigente Ley de Infracciones y Sanciones del Orden Social (I. GARCÍA-PERROTE ESCARTÍN, "Acoso sexual, acoso por razón de sexo y acoso en la Ley de Igualdad de mujeres y hombres", Relaciones Laborales, Revista crítica de teoría y práctica, no 4, 2008, p. 256 y ss.).
} 
acoso laboral o mobbing. A falta de un concepto legal, podría entenderse como un comportamiento, cuya identificación gira en torno a tres criterios $^{11}$. El primero, temporal, exige constatar la existencia de reiteración y sistematicidad en la conducta del agresor ${ }^{12}$. El segundo concierne a la gravedad de dicha conducta, que ha de consistir en una violencia extrema cuya consecuencia más significativa consiste en el aislamiento de la víctima. El tercero estriba en el dolo o culpa que atañe al agresor ${ }^{13}$, que actúa con la intención de crear el consabido entorno hostil, degradante $u$ ofensivo.

La ausencia de una definición legal, que ha hecho recaer sobre jurisprudencia y doctrina la concreción de los requisitos que este comportamiento ha de revestir, pone de manifiesto la primera carencia que presenta el marco jurídico objeto de análisis: la inseguridad jurídica. Falta certeza en cuanto a la definición del acoso laboral en tanto género, sólo hallada tras una labor de inmersión en los abundantes pronunciamientos judiciales con los cuales se ha construido la noción común esbozada líneas atrás ${ }^{14}$. También se echa de menos una mayor precisión en la delimitación de las especies de acoso de las que se ocupan las diversas normas que conforman el Derecho antidiscriminatorio español, puesto que todas ellas acusan cierta vaguedad.

La segunda flaqueza en la que incurre la normativa analizada estriba en centrarse en el sexo como factor de diferenciación, lo cual deja fuera de su ámbito de protección aquellos supuestos donde la violencia obedece a la orientación sexual de la víctima o a su identidad de género. El objeto de la LOI, que su art. 1 circunscribe a "hacer efectivo el derecho de igualdad de trato y de oportunidades entre mujeres y hombres, en particular mediante la eliminación de la discriminación de la mujer", no brinda amparo a otras causas de discriminación vinculadas al género, como noción más amplia que el sexo. Esta carencia será, en buena parte, superada mediante la aprobación del texto definitivo de la Proposición de Ley contra la discriminación por orientación sexual, identidad o expresión de género y características sexuales, y de igualdad social de lesbianas, gais, bisexuales, transexuales, transgénero e intersexuales. En su art. 3.3.6) reconoce como constitutivo de acoso discriminatorio "cualquier comportamiento o conducta que, por razones de orientación sexual, expresión o identidad de género, o pertenencia a grupo familiar, se realice con el propósito o el efecto de atentar contra la dignidad o de crear un

${ }^{11}$ C. FERREIRO REGUEIRO, "Le harcèlement sexuel. Droit italien, droit anglais, droit espagnol", Revue de droit du travail, no 5, 2013, p. 363.

12 Subrayando la frecuencia como elemento distintivo del acoso frente a otras conductas limítrofes: P. VIDAL LÓPEZ, "Diferencias entre el acoso laboral y conductas afines", Actualidad Jurídica Aranzadi, no 931, 2017, consultado en la base de datos de Westlaw (documento BIB 2018\9802), p. 2.

${ }^{13}$ C. FERREIRO REGUEIRO, ob. cit., p. 363.

14 E. SIERRA HERNÁINZ, "Los protocolos de acoso moral y política preventiva de la empresa: puntos críticos y propuestas de mejora", Revista Española de Derecho del Trabajo, no 203, 2017, consultado en la base de datos de Westlaw (documento BIB 2017\43232), p. 4. 
entorno intimidatorio, hostil, degradante, ofensivo o segregado". Otra noción amplia de acoso discriminatorio por razón de género sí ha sido adoptada por algún legislador autonómico, como el gallego, que en su Ley $2 / 2014$, de 14 de abril, por la igualdad de trato y la no discriminación de lesbianas, gays, transexuales, bisexuales e intersexuales en Galicia ${ }^{15}$, cuyo art. 3 determina la existencia de acoso "cuando se produzca una conducta que, en función de la orientación sexual o identidad de género de una persona, persiga atentar contra su dignidad y/o crear un entorno intimidatorio, hostil, degradante, humillante, ofensivo o segregador".

En el ámbito estatal, procede acudir a la prohibición del acoso discriminatorio prevista por el art. 4.2.e) ET, que sí incluye una mención expresa al motivado por la orientación sexual de la víctima, aunque sin detallar en qué ha de consistir la conducta. Como último recurso, la enumeración abierta de causas de discriminación proscritas por el art. 14 CE serviría como fundamento jurídico para la prohibición de esta conducta, así como de aquélla derivada de la identidad de género de la presunta víctima, cuya alusión evita el ET. Persiste, por tanto, cierta inseguridad jurídica que sólo una mayor concreción conceptual podría enervar.

Idéntica incertidumbre impera en cuanto concierne a los instrumentos jurídicos destinados a prevenir y actuar frente a la comisión de estas conductas con carácter previo a la vía judicial, aspecto que evidencia la tercera debilidad en la que incurre el ordenamiento jurídico español. En toda organización de recursos humanos, ya sea de naturaleza privada o pública, el acoso constituye un riesgo cuya prevención se debe articular en torno al deber genérico de protección a deducir del art. 14 de la Ley $31 / 1995$, de 8 de noviembre, de prevención de Riesgos Laborales ${ }^{16}$. Éste enuncia el derecho que ostenta todo trabajador "a una protección eficaz en materia de seguridad y salud en el trabajo".

La ausencia de un marco jurídico que permita, en primer lugar, identificar las conductas constitutivas de acoso, por más que la jurisprudencia haya asumido ese cometido, $\mathrm{y}$, en segundo lugar, dotarse de procedimientos a través de los cuales encauzar un posible supuesto, ha sido compensada por la aparición del instrumento que justifica la redacción de este trabajo: el protocolo. Al mismo hace mención la LOI, siempre y cuando esté destinado a la erradicación del acoso discriminatorio por razón de sexo en ella regulado.

De potestativa aprobación en el sector privado, la Exposición de Motivos de la LOI, alude al "mandato de aprobación de un protocolo de actuación frente al acoso sexual y por razón de sexo" entre las medidas de igualdad en el empleo en el ámbito de la Administración General del Estado. Su art. 62, no obstante, se limita a consignar el deber de las Administraciones públicas de negociar ${ }^{17}$ con la representación legal de los trabajadores, un

${ }^{15}$ DOG no 79, de 25 abril 2014.

${ }^{16}$ BOE no 269, de 10 noviembre 1995.

17 La doctrina ha advertido que el marco esbozado en la LOI "se basa en la confianza en la negociación colectiva" articulando una técnica "de respuesta mixta frente a la 
protocolo de actuación que ha de comprender, al menos: a) el compromiso de la Administración General del Estado y de los organismos públicos vinculados o dependientes de ella de prevenir y no tolerar el acoso sexual y el acoso por razón de sexo; b) la instrucción a todo el personal de su deber de respetar la dignidad de las personas y su derecho a la intimidad, así como la igualdad de trato entre mujeres y hombres; c) el tratamiento reservado de las denuncias de hechos que pudieran ser constitutivos de acoso sexual o de acoso por razón de sexo, sin perjuicio de lo establecido en la normativa de régimen disciplinario; y d) la identificación de las personas responsables de atender a quienes formulen una queja o denuncia ${ }^{18}$.

A fin de dar cumplimiento a este encargo, las diversas Administraciones públicas han aprobado una serie de protocolos. Se trata de instrumentos específicos destinados a "evitar $y$, en su caso, resolver situaciones de acoso, de forma rápida y conforme a los principios de contradicción y

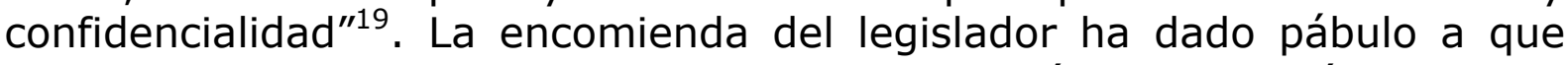
buena parte de ellos se orienten a la prevención y actuación frente a aquellas modalidades de acoso discriminatorio tipificadas por la LOI.

Como integrantes del sector público, las universidades no han permanecido ajenas a este proceso, habiendo aprobado una serie de protocolos cuya finalidad coincide, en buena medida, con la que ha inspirado las disposiciones que la LOI ha dedicado al acoso. A fin de ilustrar el papel desempeñado por este instrumento en el ámbito universitario, interesa abordar la estructura y contenido de los tres protocolos aplicables en las universidades públicas ubicadas en la Comunidad Autónoma de Galicia. Su aprobación sucesiva permitirá deducir la evolución que ha sufrido en los últimos años el modelo de protocolo aplicable a una institución que, tanto por el servicio que presta a la sociedad, como por los miembros que la integran, no está exenta de particularidades a las que este instrumento debe dar cumplida respuesta.

discriminación laboral, inspirada en esta confianza en la negociación, pero también en la contundencia de los mandatos legales comunitarios, transpuestos al Derecho español y rodeados de medidas sancionadoras encaminadas a hacerlos efectivos" (Ma. $F$. FERNÁNDEZ LÓPEZ, "Las aportaciones de la LO 3/2007", en AA. VV. La tutela laboral frente a la discriminación por razón de género, La Ley, Madrid, 2008).

18 Véase la Resolución de 28 de julio de 2011, de la Secretaría de Estado para la Función Pública, por la que se aprueba y publica el Acuerdo de 27 de julio de 2011 de la Mesa General de Negociación de la Administración General del Estado sobre el Protocolo de actuación frente al acoso sexual y al acoso por razón de sexo en el ámbito de la Administración General del Estado y de los Organismos Públicos vinculados a ella (BOE no 189 , de 8 de agosto de 2011).

${ }^{19}$ L. MELLA MÉNDEZ, "Los protocolos de acoso en los planes de igualdad en España. Una visión general", Dereito: Revista xurídica da Universidade de Santiago de Compostela, no Extra 1, 2013, p. 301. 


\section{LOS PROTOCOLOS CONTRA EL ACOSO DISCRIMINATORIO EN LAS UNIVERSIDADES PÚBLICAS DE LA COMUNIDAD AUTÓNOMA DE GALICIA}

El 26 de noviembre del año 2013, el Consejo de Gobierno de la Universidade da Coruña -en adelante, UDC - aprobó el primer protocolo encaminado a la prevención y erradicación del acoso sexual y por razón de sexo en el ámbito universitario de la Comunidad Autónoma de Galicia. La aprobación de este Protocolo para la prevención y protección frente al acoso sexual y al acoso por razón de sexo en la UDC -en adelante, PAUDC ${ }^{20}$ - vino seguida de la del Protocolo marco de actuación para la prevención y sanción del acoso sexual y por razón de sexo aprobado por el Consejo de Gobierno de la Universidad de Vigo -en adelante, PAUVigo- ${ }^{21}$, el día 26 de noviembre de 2014. Finalmente, la Universidad de Santiago de Compostela -en adelante, USC - aprobó, en el Consejo de Gobierno de 29 de julio de 2016, el Protocolo de prevención y actuación frente al acoso sexual y el acoso por razón de sexo, orientación sexual e identidad de género en la Universidad de Santiago de Compostela -en adelante, PAUSC ${ }^{22}$.

Los tres dan cumplimiento a lo previsto en los respectivos planes de igualdad diseñados en su momento por estas Universidades ${ }^{23}$. Su estructura se articula en torno a tres partes. La primera, a modo de declaración de principios, contiene una serie de consideraciones llamadas a justificar la aprobación de este instrumento, contextualizarla en el marco jurídico nacional e internacional vigente por aquel entonces y definir los objetivos que con ella pretende alcanzar la institución. La segunda acomete la difícil tarea de delimitar su ámbito de aplicación material, personal y territorial. La tercera dispone las medidas destinadas a erradicar las conductas descritas en la parte precedente $y$, a su vez, se subdivide en dos secciones. Una, dedicada a las de carácter preventivo, y otra, destinada a desarrollar el procedimiento de actuación, para el caso de que las anteriores no hubieren surtido efecto. Se diferencian así las dos funciones del protocolo que han permitido a la doctrina distinguir su faceta

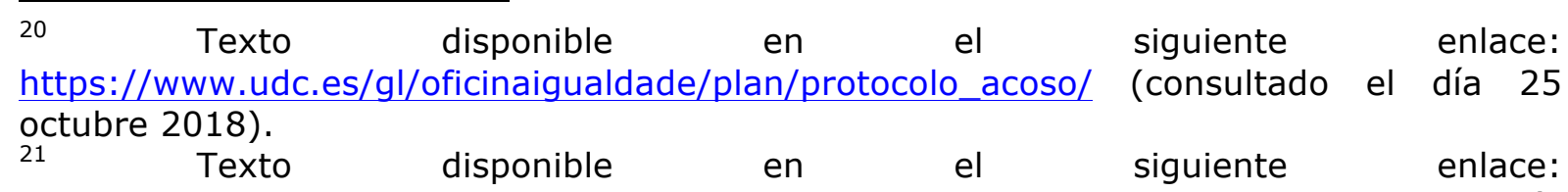
https://www.uvigo.gal/uvigo_es/administracion/igualdade/protocolo/ (consultado el día 25 octubre 2018 ).

22 Texto en el disponible siguiente enlace: http://www.usc.es/gl/servizos/oix/modules/news/news_0060.html (consultado el día 25 de octubre de 2018), del que se maneja la versión actualizada que integra las reformas llevadas a cabo por el Consejo de Gobierno en los días 27 octubre de 2016 y 14 noviembre 2017.

${ }^{23}$ A saber: I Plan de Igualdade entre Mulleres e Homes da UDC (2013-2017) (aprobado en el Consejo de Gobierno de 26 noviembre 2013), I Plan de igualdad entre mujeres y hombres de la Universidad de Vigo (2012-2014) (aprobado en la sesión del Consejo de Gobierno realizada el 12 noviembre 2012) y II Plan estratéxico de igualdade de oportunidades entre mulleres e homes da Universidade de Santiago de Compostela (2014-2018) (aprobado en el Consejo de Gobierno de 16 diciembre 2013). 
preventiva ${ }^{24}$ de la defensiva ${ }^{25}$, siendo habitual que ambas convivan en el mismo documento.

\subsection{Declaración de principios}

De singular relevancia para la adecuada interpretación de las disposiciones que les siguen son los apartados que prologan los protocolos en cuestión. EI PAUSC y el PAUVigo adoptan una terminología jurídica para introducir al lector en el contexto normativo a través de un "preámbulo". EI PAUDC, por su parte, se decanta por una breve "introducción", seguida de una "declaración de principios".

Sea como fuere, lo cierto es que estas líneas introductorias ofrecen una singular impresión acerca de la evolución de estas normas. Como se avanzaba, todas ellas se engloban dentro del acervo jurídico antidiscriminatorio, pues del acoso genérico se ocupan, de haberlos, los protocolos de prevención de riesgos laborales en sentido estricto aprobados por cada institución. No obstante, el momento en el que cada protocolo ha visto la luz condiciona lo ambicioso de sus objetivos, su estructura y, en particular la terminología en él utilizada.

Por tal motivo, no debe sorprender que el PAUDC aluda al acoso sexual y al acoso por razón de sexo, a cuya eliminación se compromete, como manifestación de "violencia de género", aun cuando la ya promulgada Ley Orgánica 1/2004, de 28 de diciembre, de Medidas de Protección Integral contra la Violencia de Género ${ }^{26}$-en adelante, LOIVG - constriñera esta denominación a la perpetrada sobre las mujeres "por parte de quienes sean o hayan sido sus cónyuges o de quienes estén o hayan estado ligados a ellas por relaciones similares de afectividad, aun sin convivencia" (art. 1). Con arreglo a esta interpretación, sólo cuando el presunto acosador sea o haya sido pareja de la víctima, podría activarse el protocolo en cuestión.

Otro significado, coherente con el ámbito de aplicación del protocolo, y que arroja una solución mucho más razonable, es el que atribuye a dicha expresión el art. 1 de la Ley 11/2007, de 27 de julio, gallega para la prevención y el tratamiento integral de la violencia de género ${ }^{27}$. A tal efecto, considera constitutivo de violencia de género "cualquier acto violento o agresión, basados en una situación de desigualdad en el marco de un sistema de relaciones de dominación de los hombres sobre las mujeres que tenga o pueda tener como consecuencia un daño físico, sexual o psicológico, incluidas las amenazas de tales actos y la coacción o privación arbitraria de la libertad, tanto si ocurren en el ámbito público como en la vida familiar o privada". Para despejar toda duda, tipifica como violencia psicológica contra la mujer las conductas ejercidas "por hombres de su entorno familiar o de su entorno social y/o laboral" [art.3.b)].

\footnotetext{
${ }^{24}$ L. MELLA MÉNDEZ, L., p. 303.

${ }^{25}$ Ibidem.

${ }^{26}$ BOE no 313, de 29 diciembre 2004.

${ }^{27}$ DOG no 152 de 7 agosto 2007.
} 
Sin dejar de aludir al acoso como conducta violenta, pero haciendo hincapié en su cariz discriminatorio, destacan los protocolos aplicables en la UVigo y en la USC. El primero de ellos alude a él como uno de los comportamientos "que más atenta contra la dignidad de la persona" y su "integridad física y psíquica", añadiendo una "declaración de principios" donde se enumeran los nueve que han de regir la actuación de la UVigo frente al acoso. Se trata, en puridad, de una enumeración de declaraciones que aluden, ora al derecho a la intimidad e integridad física y moral de las posibles víctimas, ora al propósito de mantener un entorno libre de acoso en tanto conducta discriminatoria, comprometiendo los medios humanos y materiales que sean precisos. Tampoco se olvida hacer mención a las medidas de formación, prevención y actuación a implementar, haciendo referencia, en último lugar, al carácter alternativo de este procedimiento con relación a la vía judicial.

En cuanto concierne a la contextualización del protocolo, conviene advertir el mayor detalle que muestra el PAUSC, cuyo Preámbulo comienza esbozando el marco jurídico internacional y nacional aplicable, partiendo de las normas adoptadas en el seno de la Organización de las Naciones Unidas $^{28}$ hasta llegar a las disposiciones de Derecho interno, todas ellas desarrollo del principio de igualdad proclamado, en su vertiente formal (art. 14) y material (art. 9.2) en la CE. No se olvida tampoco una referencia al acervo comunitario, que ha sentado las bases del Derecho antidiscriminatorio, ni tampoco al desarrollo que ha llevado a cabo, dentro del marco competencial que le es propio, la Comunidad Autónoma de Galicia.

Sin embargo, es necesario adentrarse en la parte dispositiva de la norma para conocer sus objetivos y los principios a los que obedece. El Capítulo I del PAUSC resume los primeros en dos: el de prevención y el de actuación. Para alcanzar el objetivo consistente en la prevención del acoso, se adelanta que la Cláusula octava enunciará las medidas de información y difusión, la novena las de formación y sensibilización, ocupándose la décima de otras medidas de prevención en sentido estricto. En cuanto a la actuación, procederá detenerse en el procedimiento descrito en el Capítulo III. Los segundos, es decir, los cuatro principios de actuación, figuran enumerados en la Cláusula segunda. Podrían sintetizarse en cinco: 1) intolerancia frente al acoso discriminatorio que se pretende combatir, 2) compromiso con la prevención y la actuación frente a aquél, 3) información e instrucción sobre este fenómeno, 4) diligencia en la tramitación y 5) confidencialidad.

\section{2. Ámbito de aplicación \\ 2.2.1. Ámbito de aplicación material}

Aunque los tres protocolos analizados se ocupen de prevenir y actuar frente a cierto tipo de acoso discriminatorio, difieren a la hora de definir

\footnotetext{
28 Véase, a tal efecto, la Convención sobre la eliminación de todas las formas de discriminación contra la mujer, hecha en Nueva York el 18 de diciembre de 1979 (BOE no 69, de 21 marzo 1984).
} 
aquél que ansían combatir. La diferencia obedece a una evolución que ha permitido visibilizar nuevas causas de discriminación no vinculadas estrictamente al sexo, sino al género, concepto que trasciende la mera condición biológica del individuo.

No es de extrañar entonces que los protocos de la UDC y la UVigo, más añejos, ciñan su protección al acoso sexual, al acoso por razón de sexo y al chantaje sexual, reproduciendo las definiciones contenidas en la $\mathrm{LOI}^{29}$, que no procede reiterar. Añade el PAUVigo una alusión a la discriminación relacionada con la maternidad que, en el seno de este protocolo, ha de entenderse a la perpetrada a través de conductas constitutivas de acoso (art. 4).

Trascendiendo el diseñado por la LOI, el PAUSC amplía su ámbito de aplicación material $u$ objetivo hasta comprender otras conductas susceptibles de instrumentalizar una discriminación por razón de género. Así, al acoso sexual y por razón de sexo se añaden el acoso por razón de orientación sexual e identidad de género. Dicha inclusión responde a una interpretación de los derechos humanos acorde con las directrices diseñadas en el art. 21 de la Carta de Derechos Fundamentales de la Unión Europea ${ }^{30}$, en la Ley $2 / 2014$, de 14 de abril, por la igualdad de trato y no discriminación de lesbianas, gays, transexuales, bisexuales e intersexuales en Galicia y en los Principios de Yogyakarta sobre la aplicación de la legislación internacional de derechos humanos en relación con la orientación sexual y la identidad de género ${ }^{31}$. Por una parte, su $12^{\circ}$ Principio enuncia el derecho al trabajo "digno y productivo", dignidad que conlleva la prestación de servicios en un entorno libre de violencia; por otra, dedica su Principio $16^{\circ}$ al derecho a la educación, conminando a los Estados a garantizar "que las leyes y políticas brinden a estudiantes, personal y docentes de las diferentes orientaciones sexuales e identidades de género una protección adecuada contra todas las formas de exclusión social y violencia, incluyendo el acoso y el hostigamiento, dentro del ámbito escolar".

En contraste con el gran avance que supone lo anterior, llama la atención que en la definición se haya recuperado la referencia al carácter "no deseado" del comportamiento en cuestión, felizmente omitida en la LOI. La previsión de un concepto más amplio en la LOI permitirá aplicar las medidas previstas por la ley en caso de comisión de la conducta. Sería oportuno, sin embargo, que los protocolos no describieran de manera restrictiva las conductas a cuya erradicación se destinan, aunque dicha definición coincida con la pergeñada por el legislador de la Unión Europea.

\footnotetext{
${ }^{29}$ Subrayando la inexistencia, por aquel entonces, de un concepto propio de acoso en el ámbito universitario: C. FARALDO CABANA, "Protocolos de actuación contra el acoso laboral en la universidad: especial referencia a la universidad da Coruña", Eguzkilore: Cuaderno del Instituto Vasco de Criminología, no. 28, 2014, p. 25.

${ }^{30}$ DOCE C 364/1, de 18 diciembre 2000.

31 Texto disponible en el siguiente enlace: http://www.refworld.org/cgibin/texis/vtx/rwmain/opendocpdf.pdf?reldoc=y\&docid=48244e9f2 (consultado el día 25 septiembre 2018).
} 
El segundo aspecto jurídico innovador introducido por el PAUSC consistió en la introducción de un listado de comportamientos constitutivos de los tipos de acoso por él perseguidos. El Anexo donde se catalogan alude a una mera relación "ejemplificativa", por lo que difícilmente cabe considerar que se trate de situaciones donde se establezca una presunción de acoso a desvirtuar por el presunto agresor. Como bien indica su enunciado, esta enumeración sólo ansía servir de guía "para ilustrar la actuación de las personas competentes" en el ámbito del protocolo, "sin voluntad de limitar su tipología y su número". La indudable ventaja que ofrece esta relación ejemplificativa estriba en completar la noción, siempre vaga, de acoso, a menudo difícil de aprehender por parte del intérprete del derecho. Obra también una finalidad disuasoria, para quien pudiera ver su conducta reflejada en alguno de los comportamientos descritos en el Anexo. Sin ánimo de reproducir el contenido íntegro del mismo, baste apuntar que comienza aludiendo a situaciones constitutivas de acoso sexual ${ }^{32}$, para luego referirse a otras típicas del acoso por razón de sexo $^{33}$, orientación sexual ${ }^{34}$ e identidad de género ${ }^{35}$, contextualizando cada una de ellas dentro del entorno universitario, a fin de facilitar su correcta identificación. Con todo, cabe imputar cierta imprecisión a la hora de describir las conductas, comprensible, por otra parte, si se tiene en cuenta la diversidad de comportamientos potencialmente constitutivos de acoso y la necesaria concesión de cierto margen de apreciación al aplicador del derecho.

\subsection{2. Ámbito de aplicación personal}

Por mor de los servicios que ofrece a la comunidad, la universidad es una institución donde convive una pluralidad de sujetos distintos por razón de su vinculación con aquélla y de las funciones que en ella representan. La consecución de un ambiente propicio a la docencia y la investigación se supedita a su desarrollo en un entorno donde impere el respeto y la igualdad. Estas condiciones que, en último término, velan por la salvaguardia de la dignidad personal, no sólo conciernen al personal al servicio de la institución. Por supuesto, a ellos se les han de aplicar con fundamento en el deber de protección deducido de la normativa de prevención de riesgos laborales. No obstante, también el alumnado merece ser objeto de protección frente a las conductas descritas, ya

32 P. ej., se citan las "invitaciones directas o indirectas de la persona agresora a la víctima relativas a la posibilidad de mantener con ella relaciones sexuales" o los "comentarios obscenos o groseros relativos al sexo en general o a la persona víctima en particular, especialmente si son reiterados, inoportunos o criticados previamente por las personas a las que van dirigidos o con las que se comparten".

${ }^{33}$ Como, "la descalificación reiterada de las mujeres o el trato ofensivo hacia ellas, por el mero hecho de ser mujeres" o la "ridiculización de las personas que asumen tareas tradicionalmente asociadas a otro sexo".

34 Así, p. ej., se alude a "comportamientos que contribuyen a crear o reproducir una percepción peyorativa de cualquier orientación distinta de la heterosexual".

35 V. gr., "la ridiculización del modo de hablar, modales y otras formas de expresión de género". 
provengan del profesorado, de otros integrantes del personal al servicio de la institución o de sus compañeros.

Paulatinamente, el protocolo ha dejado de ser sólo un instrumento de prevención de riesgos para convertirse en una herramienta reguladora de la convivencia en el ámbito universitario. Buen ejemplo de esta función renovada son cualquiera de los tres protocolos objeto de estudio. Ya el primero de ellos, el PAUDC, incluía en su ámbito de aplicación al personal docente e investigador ${ }^{36}$ y al personal de administración y servicios, pero también al alumnado. El abandono de un carácter exclusivamente laboral se descubre cuando abarca dentro de su espectro de protección a las personas autónomas relacionadas con la institución a través de un contrato de prestación de obra o servicio determinado.

Su amplitud comprende, asimismo, a otros sujetos cuya presencia en la institución no deriva de una vinculación jurídica directa. Se trata del personal afecto a contratas o subcontratas y/o puesto a disposición de la UDC por empresas de trabajo temporal (III). El proceso de externalización, a través del cual Administraciones y demás entes pertenecientes al sector público han procedido a contratar obras 0 servicios a empresas, justifica esta última previsión. El hecho de que servicios, como el de limpieza o reprografía, otrora desempeñados por personal propio de la institución, hayan pasado a ser ejecutados por los trabajadores de la empresa contratada, ha generado una suerte de relación laboral tripartita. Este fenómeno, que algún autor ubica dentro del proceso de "triangularización de las relaciones laborales"37, plantea un problema cuando el trabajador, que no ha sido contratado directamente por la universidad, pero presta servicios en sus instalaciones, es una presunta víctima o un presunto agresor. En el último caso, la universidad carece de facultades empresariales en orden a aplicar medidas disciplinarias, como sí ostenta con respecto al personal a su servicio, ya sea docente o administrativo. Tampoco podrá aplicarles la disciplina que rige al alumnado, ya que su posición en nada se parece a la de aquél. La solución urdida por este protocolo consiste en incluir a estos trabajadores dentro de su ámbito de aplicación. No obstante, se echa en falta alguna medida que garantice su efectiva aplicación. Únicamente se enuncia su difusión entre las empresas colaboradoras, a las cuales se "dará a conocer", debiendo hacerse lo propio con aquéllas que reciban alumnado de la UDC durante sus prácticas académicas.

Es sabido que la Ley 14/1994, de 1 de junio, por la que se regulan las empresas de trabajo temporal ${ }^{38}$ atribuye el poder disciplinario a aquéllas,

\footnotetext{
${ }^{36}$ EI PAUSC hace mención aparte al personal investigador en formación, de acuerdo a sus propios estatutos, así como al personal contratado para el desarrollo de actividades de investigación científica o técnica [Cláusula cuarta, ap. 1.b) y e)].

37 F. ALEMÁN PÁEZ, Curso de Derecho del Trabajo I. La relación individual de trabajo, Tecnos, Madrid, 2011 y Materiales prácticos y recursos didácticos para la enseñanza del derecho del trabajo y las políticas sociolaborales. Madrid, Tecnos, 2013 y F. VALDÉS DALRÉ, "El debate europeo sobre la «modernización del Derecho del Trabajo» y las relaciones laborales triangulares", Relaciones Laborales, n03, 2009, pp. 39 y ss.

${ }^{38}$ BOE no 131, de 2 junio 1994.
} 
sin que la empresa usuaria, a la sazón, la Universidad, pueda hacer otra cosa que poner en su conocimiento cualquier incumplimiento del trabajador. Evidentemente, la desidia de la empresa de trabajo temporal podrá hacer aconsejable prescindir de sus servicios, siendo esta inconveniencia el principal acicate para sancionar a un eventual acosador. Lo mismo sucede con las empresas que hayan sido contratadas por la institución. De ser su personal empleado la presunta víctima, entra en juego el deber de protección que se colige de la normativa rectora de la prevención de riesgos laborales, pudiendo aquél hacer uso del procedimiento de denuncia previsto en el protocolo. En este caso, la Universidad podrá actuar sobre el presunto acosador si aquél forma parte del personal a su servicio, en ejercicio de su potestad sancionadora. No obstante, cuando el trabajador de la empresa en cuestión fuera el presunto acosador, la Universidad podrá aplicar algunas medidas de prevención, e incluso llegar a instruir un procedimiento para determinar la existencia de acoso con arreglo al protocolo, pero quedará en manos del empleador aplicar la sanción disciplinaria.

Allende las facultades de la universidad queda el supuesto en el cual víctima y acosador pertenezcan a la empresa contratada. Así lo dispone expresamente el art. 3.5 PAUVigo y la Cláusula cuarta, ap. 2 del PAUSC, que no impide la "posible puesta en conocimiento de la situación denunciada a las empresas o entidades empleadoras de este personal" (Cláusula cuarta, apartado 2).

El empeño de asegurar cierta protección a este último colectivo ha justificado la previsión, en los protocolos de más reciente creación, de cláusulas sociales en la contratación pública. En concreto, la Cláusula décima, ap. 3 PAUSC dispone la inclusión en los pliegos de cláusulas administrativas particulares, como criterio de valoración de los contratos de las empresas licitadoras, el que éstas cuenten "con un protocolo o con medidas de actuación concretas frente a situaciones de acoso sexual, acoso por razón de sexo, orientación sexual e identidad de género". No se valorará la aplicación de las medidas previstas en el PAUSC, sino la mera existencia de algún protocolo o medida de actuación concreta destinada a combatir los citados tipos de acoso discriminatorio. Sin prejuzgar el contenido del protocolo o el calado de las medidas que pudieran aducir las empresas, la falta de concreción de esta cláusula social permite valorar la previsión de medidas antidiscriminatorias, cualquiera que sea su contenido. Entraña, sin embargo, un notable riesgo en la contratación pública, habida cuenta de la inseguridad jurídica que supone admitir la adopción de cualesquiera medidas de esta índole como criterio de valoración. Al tiempo, abre el camino a la aprobación de medidas con la sola finalidad de concurrir como empresa licitadora, sin que tras ellas exista un verdadero diagnóstico de las necesidades que justifican su articulación.

Más específica es la exigencia del PAUVigo, cuyo art. 6.2 impone la incorporación "en los pliegos de cláusulas administrativas particulares o en los pliegos de bases [...] como condición de ejecución del contrato una cláusula relativa al cumplimiento por parte de las contratas de lo 
establecido en este protocolo". Por añadidura, se preceptúa la inclusión en el régimen de penalidades de una cláusula cuya redacción predispone el propio protocolo en los siguientes términos: "Será falta muy grave el incumplimiento de las obligaciones establecidas en el Protocolo marco de actuación para la prevención y sanción del acoso sexual o por razón de sexo de la UVigo".

\subsection{3. Ámbito de aplicación espacial}

Menos complejo resulta, prima facie, delimitar el ámbito de aplicación espacial de estos protocolos. Al menos, así era cuando la actividad docente e investigadora tenía lugar dentro de las instalaciones de cada centro o facultad. A estas dependencias físicas hacen referencia los tres protocolos objeto de atención ${ }^{39}$, aunque el PAUVigo muestre un mayor detenimiento en la enumeración de otros espacios donde un potencial riesgo se cierne sobre los colectivos mencionados en el subepígrafe anterior. A la genérica alusión a las dependencias universitarias sigue así una explícita referencia a los "centros adscritos" a la UVigo, a "cualquier otro centro de investigación" ubicado "fuera de los campus", a "entidades públicas y privadas donde el alumnado desarrolle prácticas organizadas por la UVigo" y, por último, a "cualquier otro espacio fuera del recinto de la UVigo, siempre que la presencia en él de miembros de la comunidad universitaria derive de una actividad organizada y autorizada por la UVigo" (art. 5).

Tan bienintencionada enumeración puede, no obstante, encontrar serios obstáculos a la hora de garantizar la consecución de los objetivos del protocolo cuando, en alguno de los ámbitos espaciales citados, una conducta materialmente incluida en el protocolo se ejecute a manos de un sujeto ajeno al poder disciplinario de la institución. No es difícil concebir una situación de acoso provocada por un sujeto perteneciente a la entidad, pública o privada, donde el alumno realice sus prácticas, ni mucho menos en cualesquiera otros espacios donde la UVigo lleve a cabo una actividad "organizada y autorizada". La vinculación de la víctima con la UVigo permitiría activar el protocolo mediante la presentación de la pertinente denuncia, en los términos que se describirán seguidamente. Empero, la pertenencia del presunto agresor a otra empresa o institución dificulta la instrucción, al no ser posible ejercer sobre él compulsión alguna que le obligue a colaborar en la investigación del suceso, e impide la imposición de una sanción directa. A lo sumo, cabría presagiar un cese de la colaboración entre la Universidad y la entidad en cuestión, con arreglo a los términos reguladores de la relación que las vincule.

Tampoco resulta sencillo esclarecer el ámbito de aplicación espacial cuando la conducta constitutiva de acoso es perpetrada en un entorno virtual. La consumada implementación de herramientas de apoyo virtual a

${ }^{39}$ La alusión a "cualquier centro o espacio físico" es la adoptada por el PAUSC, cuando deslinda su "ámbito territorial" (Cláusula quinta). Abogando por una terminología amplia, el PAUDC hace referencia, asimismo, a "todos los centros e instalaciones de la UDC" (III). 
la docencia presencial y de titulaciones íntegramente impartidas a distancia ha propiciado estas situaciones. El uso y abuso de las redes sociales, tanto a nivel particular como mediante perfiles institucionales no ha hecho sino agravar la amenaza que supone la utilización de unos instrumentos virtuales que permiten una difusión de contenidos de amplio espectro mediante una conducta que apenas exige esfuerzo alguno y, por añadidura, está amparada a menudo por el anonimato que brinda un perfil falso.

Lo habitual de estas conductas no ha pasado inadvertido durante la redacción del PAUSC, que es en la actualidad el único de la Comunidad Autónoma que recoge una mención a los comportamientos que tuvieren lugar en un espacio "virtual inscrito en su ámbito organizativo y funcional". La concreción de este entorno permite deducir con cierta claridad que será competencia de la USC actuar frente a conductas constitutivas de acoso perpetradas en cualesquiera espacios virtuales ofrecidos por la institución, sobre los cuales tiene reservadas facultades de control. Éstas se desplegarían sobre el Campus Virtual de apoyo a la docencia y demás espacios web sometidos al control de la institución. En tal caso, la USC tendrá las facultades de acceso a los contenidos transmitidos por dichos medios que actualmente le confiere una interpretación jurisprudencial no del todo clara que exige un ejercicio proporcionado de las facultades empresariales, so pena de menoscabar el derecho fundamental al secreto de las comunicaciones del trabajador y, si estuvieran en peligro, el de protección de sus datos de carácter personal ${ }^{40}$.

Comprenderá el lector que la temática de este trabajo impide detallar la compleja solución urdida para dar respuesta al contenido esencial de los derechos fundamentales que conforman la esfera de privacidad que todo trabajador posee, incluso durante su prestación de servicios. El afán de no incurrir en distracciones que desvíen la atención del objeto de este estudio no empece la conveniencia de introducir algunas puntualizaciones. En primer lugar, procede destacar que la propiedad y el destino propio de los instrumentos de trabajo permiten deducir la facultad empresarial de decidir y limitar su uso. Por consiguiente, un ordenador o una herramienta virtual de titularidad de la empresa, cuya finalidad no es otra que permitir al trabajador la ejecución de su prestación de servicios, sólo podrán ser utilizados para un propósito privado cuando así se disponga y con respeto a los postulados de la buena fe contractual ${ }^{41}$. Y podrá ser la empresa, a

\footnotetext{
${ }^{40}$ Véase al respecto la jurisprudencia sentada por la STEDH de 5 septiembre 2017, caso Barbulescu contra Rumanía (TEDH 2017\61)

${ }^{41}$ A. MONTOYA MELGAR, "Nuevas tecnologías y buena fe contractual (Buenos y malos usos del ordenador en la empresa)", Relaciones Laborales, no 1, 2009, p. 5 y M. FALGUERA I BARÓ, "Uso por el trabajador del correo electrónico de la empresa para fines extraproductivos y competencias de control del empleador" Relaciones Laborales, n० 22, 2000, p. 469 y ss. Por su parte, PÉREZ DE LOS COBOS ORIHUEL y THIBAULT ARANDA consideran conforme a derecho su "uso moderado extralaboral", partiendo de su afectación a fines productivos ("El uso laboral del ordenador y la buena fe (a propósito de
} 
falta de disposición convencional reguladora de esta cuestión, la que prohíba o autorice su uso privado, quedando fuera del amparo dispensado por el derecho al secreto de las comunicaciones todo mensaje transmitido por tales cauces cuando mediare prohibición empresarial.

Llegados a esta punto, cobra especial relevancia la existencia de protocolos o reglamentos internos acerca de este particular ${ }^{42}$, como el que la USC ha elaborado para el uso de su Campus Virtual ${ }^{43}$. En lo que concierne al destinado al profesorado debe reconocerse que sus disposiciones están centradas en la eventual vulneración de los derechos de propiedad intelectual de los contenidos que en él pudieran albergarse. Sólo es posible encontrar una alusión, en su apartado 9, al contenido de las páginas web que en él pudieran referenciarse, que no podrá ser "atentatorio contra las personas o las instituciones". Cabría cuestionarse si de la limitación expresa que se hace en atención a los contenidos de dichas páginas web, que ha de ser estrictamente académico, podría deducirse una prohibición de todo uso espurio de este espacio. La ausencia de una prohibición expresa constituye un serio obstáculo, razón que permite advertir acerca de la necesidad de tener en cuenta el acoso discriminatorio a la hora de regular el uso de unas herramientas que se han mostrado especialmente proclives a servir de soporte a la violencia psicológica perpetrada en entornos docentes.

Conviene advertir acerca del cambio de criterio introducido tras la entrada en vigor de la Ley Orgánica de Protección de Datos Personales y Garantía de los Derechos Digitales ${ }^{44}$. Entre estos últimos, cuyo Título $X$ aspira a garantizar, destaca, en su art. 87, el "derecho a la intimidad y uso de dispositivos digitales en el ámbito laboral". En él se prohíbe el acceso a los contenidos derivados del uso de medios digitales facilitados por el empleador salvo que con ello se pretenda "controlar el cumplimiento de las obligaciones laborales o estatutarias" o "garantizar la integridad de dichos dispositivos". Aunque esta reforma sirva para reforzar la escasa intimidad que la anterior interpretación judicial reconocía al trabajador, no debe entenderse como un obstáculo insalvable para el control del acoso en el trabajo, ya que éste constituye un flagrante incumplimiento contractual del trabajador, como evidencia su tipificación como causa de despido disciplinario en el art. 54.2.b) ET.

Pese a lo anterior, continúa resultando conveniente para la institución dotarse de reglas relativas a la utilización de tales instrumentos, especialmente en cuanto atañe al uso privado que pudiera hacerse de los mismos. No en vano el propio apartado tercero del texto articulado

la STS de 26 de septiembre de 2007, rec. 966/2006)2, Relaciones Laborales, no 6, 2008, p. 550 y ss.)

42 J. L. GOÑI SEIN, J. L., "Nuevas tecnologías digitales, poderes empresariales y derechos de los trabajadores. Análisis desde la perspectiva del Reglamento Europeo de Protección de Datos de 2016", Revista de Derecho Social, no 78, 2017, p. 27.

43 Disponible en el siguiente enlace.

http://www.usc.es/export9/sites/webinstitucional/gl/servizos/ceta/descargas/protocolo_u so_campus_virtual.pdf (consultado el día 9 octubre 2018).

${ }^{44}$ BOE n० 294, de 6 de diciembre de 2018. 
enuncia el deber de "establecer criterios de utilización de los dispositivos digitales", a fin de proporcionar cierta seguridad jurídica en su uso. En todo caso, dichas pautas han de respetar "los estándares mínimos de protección de su intimidad de acuerdo con los usos sociales y los derechos reconocidos constitucional y legalmente", debiendo participar en su elaboración los representantes de los trabajadores. Asimismo, se prevé que el acceso por el empleador al contenido de aquellos dispositivos digitales "respecto de los que haya admitido su uso con fines privados requerirá que se especifiquen de modo preciso los usos autorizados y se establezcan garantías para preservar la intimidad de los trabajadores, tales como, en su caso, la determinación de los períodos en que los dispositivos podrán utilizarse para fines privados". Además, los trabajadores deberán ser informados de tales criterios de utilización.

El control institucional de las conductas llevadas a cabo a través de las redes sociales se revela como un terreno incluso más cenagoso que el anterior. Aquí procedería evocar la respuesta que los tribunales han proporcionado cuando una empresa, invocando las facultades que le son propias, decide aplicar medidas disciplinarias a un empleado por manifestaciones realizadas a través de su perfil en alguna red social. Cuando la conducta surte repercusión en el ámbito laboral, deviene irrelevante la propiedad del instrumento virtual (que, al tratarse de una red social, no pertenece al empresario) e incluso del instrumento físico que sirva para utilizarlo (ordenador, tableta o teléfono móvil) ${ }^{45}$. Tal sucede, por supuesto, cuando su utilización durante la jornada impida la prestación de servicios del trabajador.

Pero, además de propiciar la procrastinación, estos perfiles también sirven de medio para transmitir y publicar mensajes ofensivos, potencialmente constitutivos de acoso. Tampoco aquí resulta posible exponer con el merecido detenimiento la respuesta deparada por los tribunales. Baste con aclarar que la libertad de expresión constitucionalmente reconocida no se ha considerado un derecho fundamental susceptible de amparar ofensas, injurias o calumnias vertidas sobre la institución o cualquiera de sus integrantes. La labor de la doctrina jurisprudencial ha sido, a falta de disposiciones normativas específicas, sopesar la gravedad de cada conducta y confirmar la sanción de aquéllas que denoten especial deslealtad hacia el empleador ${ }^{46}$, generando posibles daños, pero obviando la mera difusión de anécdotas cotidianas ${ }^{47}$.

\subsection{Medidas de prevención del acoso}

Líneas atrás se avanzaban los dos objetivos primordiales de los protocolos de lucha contra el acoso discriminatorio, a saber: su prevención y la

\footnotetext{
${ }^{45}$ L. MELLA MÉNDEZ, "El uso de las redes sociales por el trabajador como incumplimiento laboral y su responsabilidad disciplinaria y contractual", en AAVV, Direito internacional do trabalho. Aplicabilidade e eficácia dos instrumentos internacionais de proteção ao trabalhador, LTr, São Paulo, 2018, p. 126.

${ }^{46}$ STSJ Cataluña de 6 noviembre 2015 (rec. no. 6.585/2015).

47 STSJ Madrid de 30 marzo 2012 (rec. no 254/2012). Véase L. MELLA MÉNDEZ, ob. últ. cit., p. 127.
} 
eventual actuación frente al mismo, cuando las medidas profilácticas han fracasado.

El laconismo del PAUVigo, cuyo art. 7 contiene una breve referencia al compromiso de la Universidad con la adopción de medidas de prevención mediante "campañas de sensibilización y formación sobre esta temática, así como cursos de prevención y formas de actuación ante tales situaciones", y la ausencia de una mención específica por parte del PAUDC, contrasta con la sistematicidad empleada por el PAUSC al dedicar su Capítulo II a las medidas que integran la actuación previa a la comisión de la infracción que nos ocupa. Éstas se dividen en medidas de información, de formación y sensibilización, y de prevención en sentido estricto.

Las primeras se articulan en torno al deber de información, del cual es destinataria toda la comunidad universitaria, acerca de la existencia del protocolo. A tal efecto, existe un deber de información genérico, que se considera cumplido mediante la publicación de aquél en la página web institucional, y otro específico, destinado a las "empresas colaboradoras, suministradoras y que trabajen en las instalaciones de la universidad". Es de advertir que este deber específico, vinculado a su aplicación a aquellos colectivos carentes de vinculación directa con la Universidad, pero potenciales víctimas o agresores por mor de su presencia en sus instalaciones, también es recogido por el PAUDC (III), junto con una alusión genérica a su difusión entre toda la comunidad universitaria valiéndose de circulares informativas y de la propia página web. Por su parte, el art. 6 del PAUVigo extiende el deber de información a toda persona, empresa e institución incluida en su ámbito de aplicación, comprometiéndose la institución a darle la "difusión necesaria".

El segundo tipo de medidas, que el PAUSC denomina "de formación y sensibilización", comprenden campañas de sensibilización y "programas formativos en materia de igualdad, género, diversidad afectivo-sexual, no discriminación y prevención y actuación" frente a las conductas constitutivas de acoso en él definidas. A causa de la variedad de sujetos a los que se destina este programa de formación y/o sensibilización, el PAUSC traza tres itinerarios formativos específicos: uno destinado al personal docente e investigador, otro al personal de administración y servicios, y un tercero al alumnado. En ambos supuestos se prevé su acreditación, bien como cursos formativos específicos, bien a través del reconocimiento de créditos ECTS, para incentivar una participación que, por lo demás, será facultativa. Con buen criterio se recomienda, en la Cláusula novena, dirigir esta acción formativa al personal con responsabilidades directivas y organizativas de equipos y centros, a la representación del alumnado y de los trabajadores, "así como a todas las personas con responsabilidades directas o indirectas en la implementación de este protocolo".

En tercer y último lugar, se alude a las medidas de prevención en sentido estricto, dentro de las cuales destacan la inclusión del acoso objeto de este protocolo en las evaluaciones del clima laboral y en las encuestas relativas a problemas, conflictos o riesgos psicosociales (Cláusulas 
décima), sin perjuicio de las evaluaciones específicas sobre la salud física y psicológica o las entrevistas personales que pudieran realizarse. Siendo esta la faceta del PAUSC que lo asemeja más a un clásico protocolo de prevención de riesgos psicosociales clásico, conviene aclarar que no es este su objetivo, para cuya consecución la USC ya dispone de otro instrumento jurídico. El carácter específico de este protocolo disculpa la parquedad de la citada cláusula, llamada a ser complementada con los demás instrumentos jurídicos de prevención de los que se ha dotado la institución ${ }^{48}$.

\subsection{Medidas de actuación frente al acoso}

\subsubsection{Procedimiento de actuación frente al acoso}

2.4.1.1. Órgano competente

Los tres instrumentos objeto de análisis coinciden en desarrollar con cierta amplitud un procedimiento a seguir cuando la actividad preventiva haya fracasado. Para ello, las tres universidades han atribuido la competencia en cuanto concierne a la tramitación de las denuncias a un órgano creado ad hoc. En el PAUDC, será una "Comisión Asesora" nombrada por el Consejo Asesor de dicha Universidad, compuesta por: a) la Directora de la Oficina de Igualdad de Género; b) la Vicerrectora del Campus de Ferrol y Responsabilidad Social, c) un representante del personal docente e investigador, d) otro representante del personal de administración y servicios, e) otro del alumnado y f) un representante de la Gerencia. En calidad de asesor de la Comisión Asesora (valga la redundancia) se menciona a un representante del Servicio de Prevención de Riesgos Laborales de la UDC (IV).

Por su parte, el PAUvigo integra en su "Comisión contra el Acoso Sexual y por Razón de Sexo", que deberá mantener la paridad entre mujeres y hombres "de conformidad con la legislación vigente", a los siguientes miembros: a) el Director de la Unidad de Igualdad de la UVigo, a modo de Presidente de la misma, b) un representante del Rector, c) un representante del personal docente e investigador, d) un representante del personal de administración y servicios, e) un representante del alumnado y f) un representante de la Gerencia (art. 9). También aquí se contempla la posibilidad de recabar la asesoría de una persona técnica especialista, a designar por la presidencia, cuando se estime necesario y previo acuerdo del CAS. En la UVigo, el nombramiento de los integrantes del CAS corre a cargo del Consejo de Gobierno a propuesta de la Comisión de Igualdad de la UVigo, limitándose su mandato a un máximo de tres años, a los que se añade una posible renovación.

El reciente PAUSC se decanta por crear una "Comisión de atención a las situaciones de acoso sexual, acoso por razón de sexo, orientación sexual e identidad de género", compuesta por cinco miembros designados por el

\footnotetext{
48 Véase, a tal efecto, el Protocolo de actuación fronte ao acoso psicolóxico, a violencia psicolóxica e outras situacións de conflito relacional no traballo, aprobado por el Consejo de Gobierno de 31 de enero de 2018, y disponible en el siguiente enlace: https://minerva.usc.es/xmlui/handle/10347/16435 (consultado el día 23 octubre 2018).
} 
Consejo de Gobierno a propuesta del Rector. En su designación se garantizará la presencia de personas integrantes del personal docente e investigador y del personal de administración y servicios. Asimismo, cuando se aborde un supuesto en el que sea parte un estudiante, se añadirán a la Comisión dos personas pertenecientes al sector del alumnado, también designadas por el Consejo de Gobierno a propuesta del Rector. Su mandato alcanza los cuatro años, previéndose la renovación parcial del Consejo cada dos años ${ }^{49}$. Su Presidencia y su Secretaría serán elegidas por la propia Comisión de entre sus miembros y también se prevé el recabar la presencia de hasta un máximo de dos asesores. No se aclara quién ha de elegir a estos últimos, pero sí se precisa que actuarán con voz pero sin voto (Cláusula sexta).

La mayor antigüedad de los protocolos aprobados por la UDC y la UVigo podría explicar que se contemple la formación en materia de acoso sexual y por razón de sexo de los miembros del órgano encargado de la tramitación del procedimiento para que puedan cumplir adecuadamente las funciones que les encomienda este protocolo (art. 10 PAUVigo). El PAUDC reconoce la necesidad de que los encargados de conocer de este procedimiento dispongan "de forma paulatina" de dicha formación, reconociendo implícitamente su carencia (IV). Es el último en ser aprobado, el PAUSC, el que se decanta por seleccionar a los integrantes en función de su formación previa, criterio digno de ser adoptado en sucesivas reformas, habida cuenta de la introducción de la perspectiva de género en la investigación que ha permitido la emergencia de profesionales dotados de formación en esta materia adquirida de forma paralela al desarrollo de su propia especialidad. Fiel a este principio, su Cláusula sexta sanciona, como criterio para su designación, la posesión de conocimientos en materia de acoso sexual, por razón de sexo, orientación e identidad sexual, así como la pertenencia a ámbitos en los cuales esta formación ha cobrado carácter transversal, como la medicina, el derecho, la psicología, la educación o la prevención de riesgos (ap. 2. pfo.20).

\subsubsection{Denuncia}

En cuanto al procedimiento en sentido estricto, conviene advertir que los tres protocolos coinciden en configurarlo como una mera alternativa a la vía jurisdiccional, que quedará expedida para la presunta víctima, tanto en el momento de activar el procedimiento a través de la denuncia, como durante la sustanciación de aquél ${ }^{50}$.

En los tres casos, su iniciación se ha de llevar a cabo a través de la pertinente denuncia, que podrá ser interpuesta por la persona afectada o su representante, pero también por una tercera persona que no ostentará

\footnotetext{
${ }^{49}$ El primer ajuste de esta rotación se solventa previendo la sustitución de dos de los miembros iniciales al cumplirse dos años contados desde la constitución de la Comisión (Cláusula sexta, ap. $3^{\circ}$ ).

50 Así, el PAUVigo advierte que su aplicación "no impedirá la utilización de las acciones judiciales previstas legalmente" (art. 13.6). Reconociendo el carácter voluntario del mismo, véase la Cláusula undécima letra d) del PAUSC y el apartado IV.a) del PAUDC.
} 
la condición de parte en el procedimiento (Cláusula duodécima PAUSC ${ }^{51}$ ). El PAUVigo admite sin ambages la idoneidad de ciertos cargos para interponer estas denuncias, aludiendo a los responsables de centros y departamentos así como a los representantes del personal y del alumnado (art. 14.2), a deducir también de la especial alusión hecha por el PAUSC a las medidas formativas dirigidas a quienes ostenten este tipo de responsabilidades (Cláusula novena). Concuerdan los tres instrumentos en requerir la ratificación de la presunta víctima para que el procedimiento pueda continuar [IV.b) PAUDC], en defecto de la cual procederá su archivo [IV.b) PAUDC y Cláusula decimotercera PAUSC].

En cuanto a la forma, el art. 3 PAUVigo es el único en admitir su interposición verbal, que se llevará a cabo en la Unidad de Igualdad, donde se procederá a levantar acta de la misma, que deberá ser firmada por la parte denunciante. De optar por su presentación escrita, tanto en los registros de la Universidad como en cualesquiera otros admitidos por la legislación administrativa, se garantiza la confidencialidad del procedimiento mediante la inserción del documento en un sobre cerrado al que se ha de acompañar un modelo de instancia, que omite toda referencia al contenido del procedimiento ${ }^{52}$. El art. 14.1 PAUVigo permite dirigir la denuncia directamente a la Presidencia de Comisión encargada de su tramitación, mientras que el PAUDC admite su interposición ante la dirección de la Oficina de Igualdad de Género o la Presidencia de de Comisión Asesora, puesto que ambos cargos recaerán en la misma persona (IV.b). EI PAUSC, por su parte, incorpora ya la posibilidad de presentar la denuncia a través de la Sede Electrónica de la USC, admitiéndose también su interposición a través de los demás medios admitidos en el procedimiento administrativo.

La interposición de la denuncia dará paso a la fase de admisión o inadmisión por parte del respectivo órgano creado por cada protocolo. El PAUVigo proporciona cinco días hábiles contados a partir de la recepción de la denuncia para llevar a cabo la convocatoria de la Comisión (CAS) a una primera reunión donde, tras un primer análisis de los hechos denunciados, se decidirá su admisión a trámite. Procederá acordar su inadmisión cuando "resulte evidente" que los hechos en ella recogidas o las personas implicadas no pertenezcan al ámbito de aplicación del PAUVigo, cuando no conste ratificación por la presunta víctima, o cuando la denuncia fuere presentada fuera de plazo (art. 16). Nótese que el PAUVigo limita la posibilidad de activar este procedimiento cuando los hechos en cuestión hayan sucedido en un plazo no superior a tres meses que, teniendo en cuenta la reiteración requerida para que una actuación violenta merezca la consideración de acoso, se computará desde la última conducta acaecida (art. 14 PAUVigo). De adoptarse esta decisión, la inadmisión a trámite será comunicada por escrito a la persona denunciante y a la víctima, si esta fuera una tercera persona.

\footnotetext{
${ }^{51}$ Admitiendo la interposición de denuncia por una tercera persona, véase también el ap. IV.a) PAUDC y el art. 14.2 del PAUVigo.

${ }^{52}$ El mismo puede consultarse en el Anexo II.
} 
Por su parte, el PAUSC concede un plazo de tres días hábiles, a contar desde la recepción de la denuncia, a la Oficina de Igualdad de Género para remitir la documentación a la Presidencia de la Comisión. Una vez se haya dado traslado de la documentación, la Presidencia deberá convocar a sus miembros para valorar, en un plazo máximo de siete días, si procede admitirla a trámite. En este caso, se optará por la inadmisión cuando la denuncia aluda a conductas o personas extrañas al ámbito de aplicación del PAUSC, decidiéndose su "archivo" si no mediara ratificación en caso de ser presentada por un tercero (Cláusula decimotercera). De inadmitirse la denuncia, se dará cuenta de esta decisión a la persona que consta como presunta víctima durante los dos días hábiles siguientes a la adopción del acuerdo.

El PAUDC es el menos prolijo en la descripción de los trámites que conlleva esta fase. Se dispone la remisión a la comisión Asesora por parte de la dirección de la Oficina de Igualdad de Género de la denuncia en un plazo máximo de cinco días, con copia al Rector.

\subsubsection{Instrucción}

La admisión a trámite de la denuncia dará paso al inicio de la fase de instrucción. EI PAUDC prevé la práctica de prueba documental y testifical, solicitada por la Comisión en la medida en que se consideren oportunas, recordando el deber de colaboración que pesa sobre todo miembro de la comunidad universitaria, que ha de facilitar la documentación e información requerida por la Comisión Asesora (IV.b PAUDC). Por su parte, el PAUVigo dispone la designación de un instructor entre los miembros de la Comisión, que deberá recabar la información que estime conveniente, practicando las pruebas testificales y documentales que considere necesarias. Se contempla "en todo caso" un trámite de audiencia durante la cual ambas partes podrán comparecer acompañadas de otra persona perteneciente a la comunidad universitaria, siempre que lo comuniquen previamente al instructor. Asimismo, el instructor podrá solicitar la colaboración de los diferentes servicios de la UVigo con competencias en esta materia, citándose, a tal efecto, el Servicio de prevención de Riesgos Laborales y el Gabinete Psicopedagógico (art. 17 PAUVigo). Esta fase de instrucción ha de demorarse, a lo sumo, veinte días hábiles contados desde la admisión a trámite de la denuncia, y finalizará con la emisión de "un informe detallado sobre las actuaciones llevadas a cabo y sus resultados". También el PAUSC, en su Cláusula decimocuarta, dispone la designación de un instructor encargado de recabar toda la información y de practicar cualesquiera pruebas testificales, documentales y "periciales o de otro tipo", siempre que se estimen pertinentes para esclarecer los hechos denunciados. Del mismo modo que en el PAUVigo, también en éste se regula un trámite de audiencia, a realizar de modo separado a fin de preservar la intimidad de las partes, al tiempo que se pretende garantizar el principio de contradicción y del derecho de defensa que han de ser salvaguardados durante todo el procedimiento. Asimismo, se concede a las partes el derecho a solicitar la práctica de cualquier prueba admitida en derecho 
hasta el momento mismo en el que la fase de instrucción culmine con la emisión del pertinente informe. Éste será emitido en el plazo máximo de un mes a contar desde la fecha de admisión a trámite de la denuncia, pudiendo prorrogarse, por autorización del Rector, hasta los dos meses, de concurrir circunstancias excepcionales, e incluso de manera indefinida, si se considera que no es posible cumplir con este plazo, y así se solicita motivadamente (Cláusula decimoquinta).

Pese a que los protocolos de la UVigo y la USC coinciden en dar por finalizada la fase de instrucción con la emisión de un informe, el PAUDC contempla una fase de mediación, para el caso de que se constate la existencia de una situación constitutiva de acoso sexual o por razón de sexo, siempre que aquélla sea aceptada por ambas partes. En caso contrario, la Comisión procederá a emitir su informe motivado en el plazo máximo de quince días desde que se haya puesto en su conocimiento la situación de acoso. En el mismo se reflejará, de existir, la existencia de acuerdo entre las partes. De no haberse alcanzado, y cuando se evidencie la existencia de acoso, la Comisión establecerá las recomendaciones que juzgue oportunas para resolver el conflicto, que pueden consistir en la apertura de un expediente disciplinario y la inmediata separación de las personas denunciante y denunciada. EI PAUDC dispone, asimismo, que para la elaboración del informe con el cual culmina la fase de instrucción, la Comisión pueda solicitar el asesoramiento de "personal externo especializado en la materia" [IV. c)].

El PAUVigo concede a la persona instructora un plazo de veinte días hábiles para la emisión del informe, contados desde la admisión a trámite de la denuncia, que presentará ante la Comisión que, a su vez, dispondrá de cinco días hábiles tras dicha presentación para adoptar un acuerdo motivado sobre la situación denunciada, que deberá ser remitido al Rectorado por su Presidencia. Más prolijo a la hora de desgranar las propuestas que puede incluir el informe, se alude, en primer lugar, a la propuesta de archivo de las actuaciones cuando se carezca de indicios determinantes de la existencia de acoso o cuando se trate de una situación no regulada por el propio PAUVigo, sin perjuicio de la apertura de una información reservada de apreciarse indicios relativos a la comisión de hechos constitutivos de otras infracciones. En segundo lugar, se propondrá la incoación de un expediente disciplinario contra la persona denunciada cuando de las actuaciones practicadas se deriven indicios suficientes de la comisión de hechos constitutivos de acoso sexual o por razón de sexo. En tercer lugar, se planteará la remisión del informe a la empresa cuando la persona presuntamente acosadora forme parte del personal afecto a contratas o subcontratas externas con la UVigo "para la adopción de las medidas que procedan". Recuérdese que el art. 6.2 del PAUVigo obliga a incluir en los pliegos de cláusulas administrativas particulares o en los pliegos de bases, como condición de ejecución del contrato, una cláusula relativa al cumplimiento por parte de las contratas de lo establecido en él, así como una cláusula en la que se tipifique como falta muy grave el incumplimiento de las obligaciones establecidas en el este instrumento. 
Por su parte, el PAUSC dispone que, en un plazo máximo de un mes a contar desde la admisión a trámite de la denuncia, más la posible prórroga a la que se hizo referencia, la Comisión elaborará un informe motivado en el cual se declare la inexistencia o la existencia de acoso con arreglo al Protocolo. Se decantará por la primera opción de no haber quedado probada de manera suficiente la conducta denunciada o de no ser ésta susceptible de ser tipificada como acoso. En este caso será el Rector quien dicte una resolución que se notificará a las partes, a la vista de la propuesta remitida por la comisión, poniendo fin a la vía administrativa, salvo el recurso potestativo de reposición. De haberse acreditado la existencia de acoso sexual, por razón de sexo, orientación sexual o identidad de género, el Rector deberá optar, bien por la apertura de un expediente disciplinario al agresor, bien por remitir lo actuado al Ministerio Fiscal. (Cláusula decimoséptima PAUSC).

Conviene advertir que el PAUSC, en su Cláusula decimosexta, encomienda a la Comisión, "si lo considera procedente", proporcionar unas "pautas de actuación" para evitar la consumación de un comportamiento constitutivo de acoso, que serán remitidas al Vicerrectorado con competencias en materia de personal docente e investigador, estudiantes o a la Gerencia, dependiendo de las personas que estén implicadas en el procedimiento. Procede adoptar estas medidas, en particular, cuando se hayan detectado comportamientos aislados que, de mediar reiteración, pudieran confluir en la consumación del acoso.

Con la finalidad de aliviar, no ya de impedir, una situación potencialmente constitutiva de acoso, tanto en el PAUVigo, como el PAUSC, prevén la adopción de medidas cautelares durante la tramitación del procedimiento. Su propósito estriba en brindar protección a la presunta víctima, por lo que no deben revestir carácter punitivo ${ }^{53}$. No obstante, tampoco deben agravar la delicada posición en la que aquélla se encuentra, razón por la cual sorprende sobremanera lo dispuesto en el art. 20 del PAUVigo, donde se contempla la posibilidad de "cambiar a la víctima de unidad administrativa, servicio, departamento, turno, centro o campus según los casos". Bien es cierto que su adopción sólo se admite de contarse con el consentimiento de la víctima, pero la violencia que se ejerce sobre ésta constituye un vicio que pone en tela de juicio su validez. Tampoco aclara el PAUSC quién ha de ver modificado su status jurídico por la aplicación de las medidas cautelares en él previstas. Su Cláusula decimoctava alude, "entre otras", al traslado temporal del puesto de trabajo y a la modificación del encargo docente, sin especificar quién ha de padecer la medida en cuestión. A fin de evitar mayores perjuicios a la víctima procede sugerir la aplicación de estas medidas al presunto agresor, de manera que las mismas permitan obtener el resultado deseado (es decir, evitar la irrogación de daños mayores) sin generar más inconvenientes de los que resulten imprescindibles para alejar a ambas partes.

53 F. R. LACOMBA PÉREZ, "Problemas aplicativos de los protocolos anti-acoso", Revista Española de Derecho del Trabajo, no 211, 2018, consultado en la Base de datos de Westlaw (documento BIB 2018\11243), p. 13. 
Por lo demás, su carácter excepcional se deduce de las "circunstancias de especial gravedad" requeridas por el PAUVigo, susceptibles de "causar un perjuicio a la víctima", o un riesgo grave e inmediato para su integridad física o psíquica, exigido por el PAUSC. Su adopción ha de ser propuesta por el órgano instructor y decidida por el Rector, de manera preferente y urgente con respecto a cualquier otro asunto, "salvo los que comprometan el correcto funcionamiento de los órganos colegiados de la Universidad (Cláusula decimoctava PAUSC).

\subsubsection{Adopción de medidas disciplinarias}

En las tres universidades, el procedimiento finaliza ante el Rector [cláusula decimoséptima PAUSC, art. 19 PAUVigo, IV.c) PAUDC], a quien incumbe adoptar las medidas disciplinarias que procedan, para lo cual ha de acudir a la normativa pertinente en función del colectivo al cual pertenezca el agresor.

Como detalla o PAUDC, de tratarse de un miembro del alumnado habrá que acudir al Decreto de 8 de septiembre de 1954 por el que se aprueba el Reglamento de disciplina académica de los Centros oficiales de Enseñanza Superior y de Enseñanza Técnica dependientes del Ministerio de Educación Nacional ${ }^{54}$. Entre las faltas graves en él tipificadas, que a día de hoy podrían dar cabida a comportamientos constitutivos de acoso, figuran "la injuria, ofensa o insubordinación contra las autoridades académicas o contra los Profesores" [art. 5.a).2a] o "la ofensa grave, de palabra u obra, a compañero, funcionarios y personal dependiente del Centro" [art. 5.a).2a]". No resulta difícil advertir que su comisión no exige que medie reiteración, ausencia de la cual se deduce que las mismas aluden a comportamientos menos graves que el que nos ocupa. No por ello las "correcciones aplicables" son menos severas, pues pasan, por ejemplo, por la inhabilitación temporal o perpetua para cursar estudios en los Centros docentes. Más complejo resulta determinar el régimen disciplinario aplicable a los diversos colectivos que integran el personal de cada universidad. A tal efecto, procede realizar una remisión a la normativa aplicable a cada uno de ellos que dependerá de su vinculación con la institución.

Por último, en algunos protocolos se advierte acerca de las consecuencias de la interposición de denuncias tras las cuales se aprecie mala fe o aportación de pruebas falsas, conducta que puede dar lugar a la apertura del correspondiente expediente disciplinario, en este caso, a la persona denunciante [Cláusula decimosexta PAUSC y 18.2.a).i PAUVigo, en este caso, a propuesta de la Comisión].

\section{CONCLUSIÓN}

La sucesión de protocolos aprobados por las universidades públicas sitas en la Comunidad Autónoma de Galicia ilustra la evolución que este instrumento ha experimentado a lo largo del último lustro. Ya en el primero de ellos -PAUDC- se advierte la principal singularidad que ha

${ }^{54}$ BOE no 285, de 12 octubre 1954. 
distinguido a esta herramienta jurídica de otras restringidas a la prevención de riesgos laborales. Estriba ésta en su ámbito subjetivo de aplicación, universal, al ser extensible a todo aquel individuo expuesto al riesgo que se pretende evitar y/o perseguir, goce o no de vinculación directa con la universidad. Fieles a esta nueva concepción del protocolo, como garante de la convivencia en la comunidad universitaria, los siguientes -PAUVigo y PAUSC- han adoptado el mismo enfoque, sólo plenamente efectivo de venir acompañado por medidas destinadas a garantizar la efectiva aplicación de dicha protección al personal no directamente vinculado a la universidad. A tal efecto, conviene reparar en el protagonismo adquirido por las cláusulas sociales en la contratación pública, que obligan a tomar el consideración la existencia de un protocolo como criterio de valoración (PAUSC) o que prevén la inclusión del cumplimiento de sus disposiciones entre las condiciones de ejecución recogidas en los pliegos de cláusulas administrativas, atribuyendo consecuencias jurídicas a su inobservancia en el régimen de penalidades (PAUVigo).

No obstante, sólo el PAUSC se atrevió a avanzar un paso significativo con respecto a lo preceptuado por la LOI, cuando dispensó protección al acoso discriminatorio por razón de orientación sexual e identidad de género, superando el sexo como factor a tomar en consideración. La ausencia de un marco jurídico específico a nivel estatal destinado a la prevención y erradicación de estas otras modalidades de violencia discriminatoria hace especialmente recomendable su inclusión en el protocolo, razón que permite considerar este rasgo del PAUSC como un ejemplo a seguir.

Pero no sólo merece especial alusión el tránsito de la lucha contra la discriminación por razón de sexo a aquélla que obedece a otras características vinculadas al género. También la toma en consideración de la violencia perpetrada a través de entornos virtuales supone un avance que todo futuro protocolo deberá hacer suyo, regulando y restringiendo el uso de estos nuevos ecosistemas tan proclives a dar cabida a estas conductas. La aprobación y difusión de protocolos internos que encuadren el uso privado que pudiera hacerse de estas plataformas, y especifiquen las conductas cuya comisión está prohibida, constituye una tarea a acometer por las diversas universidades. En particular, el marco normativo esbozado en la Ley Orgánica de Protección de Datos Personales y Garantía de los Derechos Digitales hace imprescindible su concreción por parte del empleador, debiendo contar para ello con la participación de los representantes de los trabajadores.

El elenco de conductas típicas constitutivas del acoso discriminatorio con el que se ilustra el ámbito de aplicación del PAUSC constituye la última innovación que presenta su configuración. Pese a su carácter ejemplificativo, la virtualidad preventiva que entraña la mención de una serie de comportamientos en los que un potencial infractor pudiera identificar su proceder resulta indudable. $Y$, desde una perspectiva ejecutiva, facilitará en buena medida la labor del órgano encargado de la instrucción del procedimiento. 
En cuanto concierne a las medidas de actuación, los principales aspectos a mencionar conciernen, en primer lugar, a la vertiente preventiva del protocolo $y$, en segundo término, a su faceta defensiva. Destaca, en el plano preventivo, el diseño de itinerarios de formación específicos previstos en el PAUSC, en atención a las necesidades de los colectivos a los que estén destinados. Su desarrollo continuado a través de herramientas basadas en el aprendizaje a través de las nuevas tecnologías o acercando esta realidad al alumnado mediante método del aprendizajeservicio constituiría el siguiente reto a asumir.

En el plano ejecutivo, se considera crucial la configuración de un órgano instructor de composición interdisciplinar caracterizado por la especialización profesional, también en materia de género, de los miembros que lo integran. La dificultad que supone la identificación y clasificación de estas conductas, y la complejidad que entraña la adopción de las medidas cautelares o disciplinarias adecuadas exigen la intervención de profesionales cualificados. Habida cuenta del desarrollo que ha adquirido en los últimos años la perspectiva de género en la docencia y en la investigación, conviene hacer de los méritos formativos y/o investigadores de los miembros del órgano instructor un presupuesto indispensable para su nombramiento.

\section{BIBLIOGRAFÍA}

F. ALEMÁN PÁEZ, Curso de Derecho del Trabajo I. La relación individual de trabajo, Tecnos, Madrid, 2011.

F. ALEMÁN PÁEZ, Materiales prácticos y recursos didácticos para la enseñanza del derecho del trabajo y las políticas sociolaborales. Madrid, Tecnos, 2013.

M. FALGUERA I BARÓ, "Uso por el trabajador del correo electrónico de la empresa para fines extraproductivos y competencias de control del empleador" Relaciones Laborales, no 22, 2000.

C. FARALDO CABANA, "Protocolos de actuación contra el acoso laboral en la universidad: especial referencia a la universidad da Coruña", Eguzkilore: Cuaderno del Instituto Vasco de Criminología, no. 28, 2014.

C. FERREIRO REGUEIRO, "Le harcèlement sexuel. Droit italien, droit anglais, droit espagnol", Revue de droit du travail, no 5, 2013.

I. GARCÍA-PERROTE ESCARTÍN, "Acoso sexual, acoso por razón de sexo y acoso en la Ley de Igualdad de mujeres y hombres", Relaciones Laborales, Revista crítica de teoría y práctica, no 4, 2008.

J. L. GOÑI SEIN, J. L., "Nuevas tecnologías digitales, poderes empresariales y derechos de los trabajadores. Análisis desde la perspectiva del Reglamento Europeo de Protección de Datos de 2016", Revista de Derecho Social, no 78, 2017.

F. R. LACOMBA PÉREZ, "Problemas aplicativos de los protocolos antiacoso", Revista Española de Derecho del Trabajo, no 211, 2018.

L. MELLA MÉNDEZ, "El uso de las redes sociales por el trabajador como incumplimiento laboral $y$ su responsabilidad disciplinaria y contractual", en AA. VV., Direito internacional do trabalho. 
Aplicabilidade e eficácia dos instrumentos internacionais de proteção ao trabalhador, LTr, São Paulo, 2018.

L. MELLA MÉNDEZ, "Harassment Protocols in Spain: The Case of Universities", en AAVV, Psychosocial Risks in Labour and Social Security Law. A Comparative Legal Overview from Europe, North America, Australia and Japan, Springer, 2017.

L. MELLA MÉNDEZ, "Los protocolos de acoso en los planes de igualdad en España. Una visión general", Dereito: Revista xuridica da Universidade de Santiago de Compostela, nº Extra 1, 2013.

A. MONTOYA MELGAR, "Nuevas tecnologías y buena fe contractual (Buenos y malos usos del ordenador en la empresa)", Relaciones Laborales, no 1, 2009.

F. PÉREZ DE LOS COBOS ORIHUEL y J. THIBAULT ARANDA consideran conforme a derecho su "uso moderado extralaboral", partiendo de su afectación a fines productivos ("El uso laboral del ordenador y la buena fe (a propósito de la STS de 26 de septiembre de 2007, rec. 966/2006)2, Relaciones Laborales, no 6, 2008.

N. SERRANO ARGÜESO, "Dificultades para reconocer la presencia de acoso discriminatorio. El frecuente ejemplo del acoso por razón de sexo", Revista Doctrinal Aranzadi Social, vol. 4, no 7, 2011.

E. SIERRA HERNÁINZ, "Los protocolos de acoso moral y política preventiva de la empresa: puntos críticos y propuestas de mejora", Revista Española de Derecho del Trabajo, no 203, 2017.

VALDÉS DAL-RÉ, "El debate europeo sobre la «modernización del Derecho del Trabajo» y las relaciones laborales triangulares", Relaciones Laborales, n03, 2009.

R. VALLEJO DACOSTA, "Acoso sexual y acoso por razón de sexo: riesgos de especial incidencia en la mujer trabajadora", Trabajo: Revista andaluza de relaciones laborales, no 17, 2006.

P. VIDAL LÓPEZ, "Diferencias entre el acoso laboral y conductas afines", Actualidad Jurídica Aranzadi, no 931, 2017. 